\title{
Diverse Interactions of N-Methyl Glycine in Aqueous Paracetamol Solution with the Manifestation of Solvation Consequences
}

\author{
Habibur Rahaman¹, Kalipada Sarkar², Debasmita Das³, Mahendra Nath Roy3,* \\ ${ }^{1}$ Department of Chemistry, Pedong Government College, Kalimpong - 734 311, West Bengal, India. \\ ${ }^{2}$ Department of Chemistry, Islampur College, Uttar Dinajpur - 733 202, West Bengal, India. \\ ${ }^{3}$ Department of Chemistry, University of North Bengal, Darjeeling - 734 013, West Bengal, India.
}

\section{ART ICLE DETAILS}

\section{Article history:}

Received 30 November 2018

Accepted 18 December 2018

Available online 05 January 2019

\section{Keywords:}

N-Methyl Glycine

Solute-Solvent Interactions

Paracetamol

\begin{abstract}
A B S T R A C T
The apparent molar volume $\left(\phi_{V}\right)$ and viscosity B-coefficient of N-methyl glycine of $0.01 \mathrm{M}, 0.02 \mathrm{M}$ and $0.03 \mathrm{M}$ aqueous solutions have been estimated in presence of paracetamol at three temperatures namely $298.15 \mathrm{~K}, 303.15 \mathrm{~K}$ and $308.15 \mathrm{~K}$ from physicochemical study such as density $(\rho)$ and viscosity $(\eta)$ and refractive index measurements and ${ }^{1} \mathrm{H}$ NMR spectroscopy. The volumetric study was employed to evaluate limiting apparent molar volumes $\left(\phi_{V}{ }^{0}\right)$ and experimental slopes $\left(S_{V}^{*}\right)$ by using Masson equation for explaining solute-solvent and solute-solute interactions, respectively. The nature of group interactions between the solute, solvent and co-solute have been examined from limiting apparent molar volumes of transfer $\left(\Delta \phi_{v}{ }^{0}\right)$ values. The viscosity data were employed to determine viscosity $A$ and $B$ coefficients from Jones-Dole equation and the resulting parameters were used to examine the solutesolute and solute-solvent interactions in the solutions. Molar refraction values calculated from refractive indices by applying Lorentz-Lorenz equation were used to depict the intermolecular interactions between $\mathrm{N}$-methyl glycine and paracetamol in their aqueous solution. However, the ${ }^{1} \mathrm{H} N \mathrm{NR}$ spectroscopy supports the existence of diverse interactions concretely.
\end{abstract}

\section{Introduction}

The native confirmations of proteins depend on to several non-covalent interactions such as hydrogen bonding, electrostatic and hydrophobic interactions which may originate from surrounding solute and solvent molecules $[1,2]$. So physicochemical properties of the proteins are influenced greatly by the presence of surrounding solute and solvent molecules. Physiochemical study of proteins provides many valuable information like hydration, solubility, stabilization and enzyme activity which are taking place in biochemical and physiological processes of living organism [3-5]. The nature of interaction of drug molecules with protein may also be understood from Physiochemical measurements.

World's most popular and most commonly used analgesic and antipyretic medicines from cradle to grave is paracetamol which is readily available and inexpensive also [6-8]. Chemical name of paracetamol is $\mathrm{N}$ para-methyl aminophenol. It was introduced into the market by as an analgesic and antipyretic medicine by McNeil Laboratories mainly for children. After 1961 it became the most frequently sold analgesic medications. Its use as an analgesic is most tolerable than the other nonsteroidal drugs (NSAIDs) which should not be used by the people with bronchial asthma, hemophilia, salicylate-sensitized people, peptic ulcer disease, pregnant or breastfeeding women and children under 12 years of age $[9,10]$. Currently the use of aspirin as antipyretic and analgesic has been declined due some adverse effects and parallelly the use of paracetamol has been increased. Paracetamol has now been an appropriate analgesic for all age groups.

In continuance of our earlier works [11-15], we attempted to examine the nature of solute-solvent/co-solute interactions of $\mathrm{N}$-methyl glycine in aqueous solutions of paracetamol at $298.15 \mathrm{~K}, 303.15 \mathrm{~K}$ and $308.15 \mathrm{~K}$. The densities, viscosities and refractive indices of $0.01,0.02$ and $0.03 \mathrm{M}$ aqueous $\mathrm{N}$-methyl glycine solutions at $298.15 \mathrm{~K}, 303.15 \mathrm{~K}$ and $308.15 \mathrm{~K}$ are reported in Table 1 and densities, viscosities and refractive indices of aqueous $\mathrm{N}$-methyl glycine solutions in presence of paracetamol at 298.15 $\mathrm{K}, 303.15 \mathrm{~K}$ and $308.15 \mathrm{~K}$ are reported in Table 2. From the volumetric measurements we calculated limiting apparent molar volume $\left(\phi_{\nu}{ }^{0}\right)$,

experimental slopes $\left(S_{V}^{*}\right)$, transfer volume $\left(\Delta \phi_{V}{ }^{0}\right)$ and from the viscometric measurements we calculated viscosity $A$ and $B$ coefficients to analyse the nature of solute-solvent/ co-solute interactions. The refractive index data helps to find the molar refraction $\left(R_{M}\right)$ which also helps to elucidate the interaction between solute and co-solute in aqueous medium.

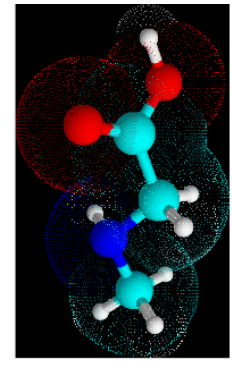

$\mathrm{N}$-methvl glvcine

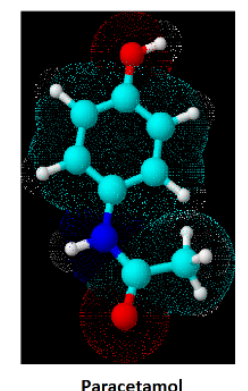

Fig. 1 Molecular structures of N-methyl glycine and paracetamol

\section{Experimental Methods}

\subsection{Source and Purity Samples}

The studied N-methyl glycine and co-solute paracetamol of purist grade was purchased from Sigma-Aldrich, Germany and was used as purchased. The mass purity of salts was $\geq 0.99$. The salts were dried from moisture at $353.15 \mathrm{~K}$ for $48 \mathrm{~h}$, and then they were cooled and store in a desiccator prior to use.

\subsection{Apparatus and Procedure}

The density $(\rho)$ measurements were done by vibrating-tube Anton Paar Density-Meter (DMA 4500M) with an accuracy of $0.00001 \times 10^{-3}\left(\mathrm{kgm}^{-3}\right)$. The density meter was calibrated by using double-distilled water and dry air before taking the densities of our studied solutions [16]. The instrument has temperature monitoring system with the precision \pm 0.01 K. 
The viscosity was determined using of Brookfield DV-III Ultra Programmable Rheometer having spindle size- 42 fitted. The Rheometer was fitted with Digital Bath TC-500 which has a precision of $\pm 0.001 \mathrm{~K}$. The viscosity was measured after calibrating the Rheometer with doubly distilled water and purified methanol [17]. The uncertainty in viscosity measurements is within $\pm 0.003 \mathrm{mPas}$.

Mass measurements for preparation of stock solutions were done by Mettler AG-285 electronic balance with a precision of $\pm 0.0003 \times 10^{-3} \mathrm{~kg}$. The uncertainty in molality of solution is approximately $\pm 0.0001 \mathrm{molkg}^{-1}$ Acceptable precautions were followed to minimize evaporation losses during the measurements.

Table 1 Experimental values of density $(\rho)$, viscosity $(\eta)$ and refractive index $\left(n_{D}\right)$ of different molality of aqueous $\mathrm{N}$-methyl glycine solution at $298.15 \mathrm{~K}, 303.15 \mathrm{~K}$ and $308.15 \mathrm{~K}$

\begin{tabular}{llllllll}
\hline Conc. & \multicolumn{2}{l}{$\rho \times 10^{-3} / \mathrm{kg}^{-3} \mathrm{~m}^{-3}$} & \multicolumn{3}{c}{$\eta \mathrm{mP.s}$} & $\mathrm{n}_{\mathrm{D}}$ \\
\cline { 2 - 8 } & $298.15 \mathrm{~K}$ & $303.15 \mathrm{~K}$ & $308.15 \mathrm{~K}$ & $298.15 \mathrm{~K}$ & $303.15 \mathrm{~K}$ & $308.15 \mathrm{~K}$ & $298.15 \mathrm{~K}$ \\
\hline $0.01 \mathrm{M}$ & 0.99756 & 0.99621 & 0.99460 & 0.8956 & 0.80910 & 0.6804 & 1.3319 \\
$0.02 \mathrm{M}$ & 0.99782 & 0.99649 & 0.99486 & 0.8984 & 0.8116 & 0.6831 & 1.3325 \\
$0.03 \mathrm{M}$ & 0.99817 & 0.99679 & 0.99515 & 0.9016 & 0.8140 & 0.6859 & 1.3327 \\
\hline
\end{tabular}

Table 2 Density $(\rho)$ and viscosity $(\eta)$ and refractive index $\left(n_{D}\right)$ of different molality of aqueous N-methyl glycine in aqueous paracetamol solution at $298.15 \mathrm{~K}, 303.15 \mathrm{~K}$ and $308.15 \mathrm{~K}$

\begin{tabular}{|c|c|c|c|c|c|c|c|}
\hline \multirow{3}{*}{$\begin{array}{l}\text { Molality } \\
\text { Molkg-1 }\end{array}$} & \multirow{2}{*}{\multicolumn{3}{|c|}{$\begin{array}{l}\rho \times 10^{-3} \\
\mathrm{kgm}^{-3}\end{array}$}} & \multirow{2}{*}{\multicolumn{3}{|c|}{$\begin{array}{l}\eta \\
\mathrm{mPs}\end{array}$}} & \multirow[t]{2}{*}{$\mathrm{n}_{\mathrm{D}}$} \\
\hline & & & & & & & \\
\hline & $298.15 \mathrm{~K}$ & $303.15 \mathrm{~K}$ & $308.15 \mathrm{~K}$ & $298.15 \mathrm{~K}$ & $303.15 \mathrm{~K}$ & $308.15 \mathrm{~K}$ & $298.15 \mathrm{~K}$ \\
\hline \multicolumn{8}{|c|}{$0.01 \mathrm{M} \mathrm{N}$-methyl glycine solution } \\
\hline 0.013 & 0.998 & 0.99664 & 0.99503 & 0.9053 & 0.8179 & 0.6882 & 1.3321 \\
\hline 0.023 & 0.99836 & 0.99700 & 0.99538 & 0.9122 & 0.8242 & 0.6947 & 1.3323 \\
\hline 0.045 & 0.999065 & 0.997725 & 0.99611 & 0.9264 & 0.8373 & 0.7076 & 1.3327 \\
\hline 0.057 & 0.99944 & 0.99811 & 0.9965 & 0.9434 & 0.8537 & 0.7231 & 1.3329 \\
\hline 0.072 & 0.99990 & 0.99859 & 0.99699 & 0.9594 & 0.8703 & 0.7386 & 1.3331 \\
\hline \multicolumn{8}{|c|}{$0.02 \mathrm{M} \mathrm{N}$-methyl glycine solution } \\
\hline 0.013 & 0.99824 & 0.996904 & 0.99527 & 0.9079 & 0.8204 & 0.6909 & 1.33272 \\
\hline 0.023 & 0.99859 & 0.99725 & 0.99562 & 0.9148 & 0.8267 & 0.6974 & 1.33286 \\
\hline 0.045 & 0.999295 & 0.99798 & 0.99635 & 0.9292 & 0.8408 & 0.7110 & 1.33313 \\
\hline 0.057 & 0.99967 & 0.998382 & 0.99676 & 0.9464 & 0.8572 & 0.7262 & 1.33327 \\
\hline 0.072 & 1.00014 & 0.99889 & 0.99726 & 0.9632 & 0.8738 & 0.7423 & 1.33345 \\
\hline \multicolumn{8}{|c|}{$0.03 \mathrm{M} \mathrm{N}$-methyl glycine solution } \\
\hline 0.013 & 0.99858 & 0.99719 & 0.99554 & 0.9111 & 0.8228 & 0.6939 & 1.33319 \\
\hline 0.023 & 0.99892 & 0.99754 & 0.99588 & 0.9181 & 0.8297 & 0.7005 & 1.33332 \\
\hline 0.045 & 0.99962 & 0.99828 & 0.99662 & 0.9334 & 0.8442 & 0.7152 & 1.33358 \\
\hline 0.057 & 0.99999 & 0.99869 & 0.99703 & 0.9506 & 0.8608 & 0.7309 & 1.33372 \\
\hline 0.072 & 1.00046 & 0.99921 & 0.99755 & 0.9674 & 0.8782 & 0.7468 & 1.3339 \\
\hline
\end{tabular}

\section{Results and Discussion}

\subsection{Density}

Apparent molar volumes $\left(\phi_{V}\right)$ of $\mathrm{N}$-methyl glycine in aqueous paracetamol solution were determined from the densities of the solution using the following equation [18],

$$
\phi_{V}=M / \rho-1000\left(\rho-\rho_{0}\right) /\left(m \rho \rho_{0}\right)
$$

where $M$ is the molar mass of N-methyl glycine, $\rho_{0}$ and $\rho$ is the densities of solvent and solution respectively and $\mathrm{M}$ is the molality of the solution. The $\phi_{V}$ values of $\mathrm{N}$-methyl glycine in aqueous paracetamol solution at 298.15 $\mathrm{K}, 303.15 \mathrm{~K}$ and $308.15 \mathrm{~K}$ are shown in Tables 3-5 respectively.

Table 3 Apparent molar volume, $\left(\phi_{V}\right)$ and $\left(\eta / \eta_{0}-1\right) / \sqrt{m}$ of $0.01 \mathrm{~m}, 0.02 \mathrm{M}$ and 0.03 $\mathrm{M} \mathrm{N}$-methyl glycine in aqueous paracetamol solution at $298.15 \mathrm{~K}, 303.15 \mathrm{~K}$ and $308.15 \mathrm{~K}$

\begin{tabular}{|c|c|c|c|c|c|c|c|}
\hline \multirow[t]{2}{*}{ Molality } & $\begin{array}{l}\phi_{V} \times 10^{6} \\
\left(\mathrm{~m}^{3} \mathrm{~mol}^{-}\right. \\
\left.{ }_{1}\right)\end{array}$ & $\begin{array}{l}\left(\eta / \eta_{0}-1\right) \\
/ \sqrt{m} \\
\left(\text { molkg-1) }^{-1}\right) \\
1 / 2\end{array}$ & $\begin{array}{l}\phi_{V} \times 10^{6} \\
\left(\mathrm{~m}^{3} \mathrm{~mol}^{-}\right. \\
\left.{ }^{1}\right)\end{array}$ & $\begin{array}{l}\left(\eta / \eta_{0}-1\right) \\
/ \sqrt{m} \\
\left(\mathrm{molkg}^{-1}\right) \\
1 / 2\end{array}$ & $\begin{array}{l}\phi_{V \times 10^{6}} \\
\left(\mathrm{~m}^{3} \mathrm{~mol}^{-}\right. \\
\left.{ }^{1}\right)\end{array}$ & $\begin{array}{l}\eta / \eta_{0-} \\
1) / \sqrt{m} \\
(\mathrm{molkg}- \\
1)^{-1 / 2}\end{array}$ & $R_{M}$ \\
\hline & \multicolumn{2}{|l|}{$298.15 \mathrm{~K}$} & \multicolumn{2}{|l|}{$303.15 \mathrm{~K}$} & \multicolumn{2}{|l|}{$308.15 \mathrm{~K}$} & \\
\hline \multicolumn{8}{|c|}{$0.01 \mathrm{M} \mathrm{N}$-methyl glycine } \\
\hline 0.013 & 81.9779 & 0.097 & 82.8475 & 0.097 & 82.9254 & 0.1025 & 24.0760 \\
\hline 0.023 & 82.5861 & 0.122 & 82.8701 & 0.123 & 83.3881 & 0.1386 & 24.0806 \\
\hline 0.045 & 83.6520 & 0.162 & 83.4952 & 0.164 & 83.6878 & 0.1885 & 24.0898 \\
\hline 0.057 & 84.0840 & 0.176 & 83.7982 & 0.183 & 83.8793 & 0.2124 & 24.0939 \\
\hline 0.072 & 84.5290 & 0.193 & 84.0372 & 0.208 & 83.9781 & 0.2355 & 24.0959 \\
\hline
\end{tabular}

https://doi.org/10.30799/jacs.199.18040403

Cite this Article as: Habibur Rahaman, Kalipada Sarkar, Debasmita Das, Mahendra Nath Roy, Diverse interactions of N-methyl glycine in aqueous paracetamol solution with the manifestation of solvation consequences, J. Adv. Chem. Sci. 4(4) (2018) 601-605.

\begin{tabular}{lrllllll}
\hline 0.02 & M N-methyl glycine & & & & & \\
0.013 & 83.5737 & 0.095 & 84.1238 & 0.097 & 84.5304 & 0.1021 & 24.1110 \\
0.023 & 83.8852 & 0.120 & 84.1716 & 0.123 & 84.4747 & 0.1380 & 24.1119 \\
0.045 & 84.3100 & 0.162 & 84.0420 & 0.170 & 84.1249 & 0.1925 & 24.1125 \\
0.057 & 84.6009 & 0.178 & 83.9259 & 0.188 & 83.8662 & 0.2140 & 24.1126 \\
0.072 & 84.7955 & 0.197 & 83.7422 & 0.212 & 83.8241 & 0.2399 & 24.1131 \\
0.03 & M & -methyl glycine & & & & & \\
0.013 & 84.6007 & 0.094 & 85.2365 & 0.097 & 86.1321 & 0.1043 & 24.1338 \\
0.023 & 84.7413 & 0.121 & 84.5944 & 0.127 & 85.5587 & 0.1404 & 24.1340 \\
0.045 & 84.9404 & 0.166 & 84.0268 & 0.175 & 84.5599 & 0.2014 & 24.1343 \\
0.057 & 85.1125 & 0.182 & 83.7691 & 0.193 & 84.2069 & 0.2233 & 24.1344 \\
0.072 & 85.1969 & 0.200 & 83.4466 & 0.218 & 83.8095 & 0.2463 & 24.1348 \\
\hline
\end{tabular}

According to Masson, the apparent molar volumes, $\phi_{V}$, vary with the square root of the molal concentration, $\sqrt{m}$ as per following linear equation,

$$
\phi_{\mathrm{V}}=\phi_{\mathrm{V}^{0}}+\mathrm{S}_{\mathrm{V}}{ }^{*} \sqrt{\mathrm{m}}
$$

where $\phi_{V}{ }^{0}$ is the limiting apparent molar volume of $\mathrm{N}$-methyl glycine and $S_{V}^{*}$ is the experimental slope. The plots of $\phi_{V}$ against $\sqrt{m}$ of aqueous $\mathrm{N}$ methyl glycine solutions at $298.15 \mathrm{~K}, 303.15 \mathrm{~K}$ and $308.15 \mathrm{~K}$ in presence of paracetamol gives a linear line with a slope of $S_{V}{ }^{*}$ and an intercept of $\phi_{V}{ }^{0}$.

The values of $\phi_{V}{ }^{0}$ and $S_{V}{ }^{*}$ of $\mathrm{N}$-methyl glycine in aqueous paracetamol solutions at $298.15 \mathrm{~K}, 303.15 \mathrm{~K}$ and $308.15 \mathrm{~K}$ are mentioned in Table 4 and Fig. 2.

The $\phi_{V}{ }^{0}$ value indicates the extent of solute-solvent interaction [19]. It is observed that $\phi_{V}{ }^{0}$ values for $\mathrm{N}$-methyl glycine solutions in paracetamol are positive and increase with the increasing molarities $\mathrm{N}$-methyl glycine and also with temperature which is shown in Table 4 and Fig. 2.

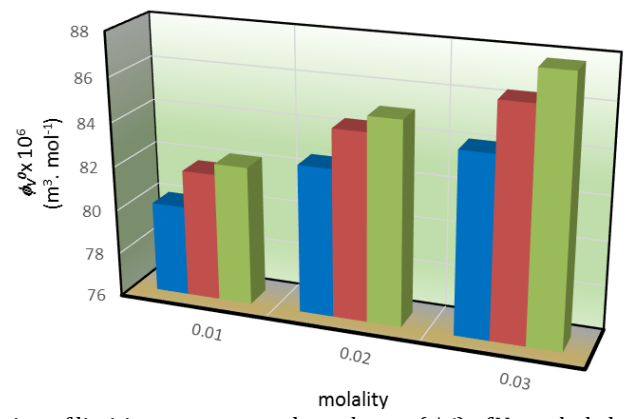

Fig. 2 Variation of limiting apparent molar volumes $\left(\phi_{V}{ }^{0}\right)$ of $\mathrm{N}$-methyl glycine solution in paracetamol solution at different temperatures

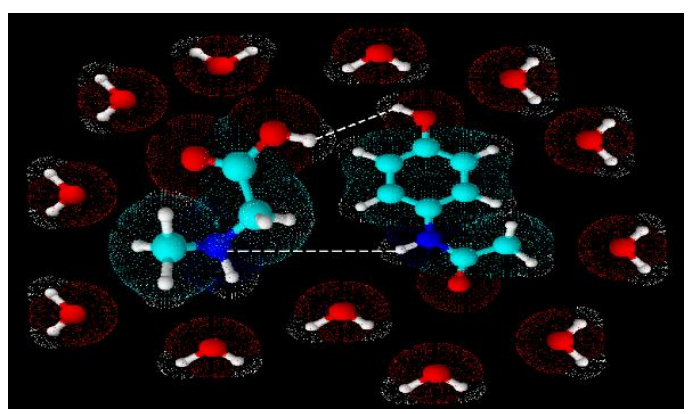

Fig. 3 Molecular interactions between N-methyl glycine with paracetamol in aqueous medium

The tendency indicates the presence of strong solute-solvent interactions which increase with molarity of $\mathrm{N}$-methyl glycine and temperatures. The interaction arises from the hydrophilic-hydrophilic group interaction between solute and co-solute molecules. The interaction of N-methyl glycine with paracetamol in aq. medium is displayed in Fig. 3. With increasing temperature the secondary solvation layer is released into the bulk solvent leading to the expansion of solution. As a result, the $\phi_{V}{ }^{0}$ values of $\mathrm{N}$-methyl glycine in aqueous paracetamol solutions increase with increase in temperature.

The parameter $\mathrm{S}_{\mathrm{V}}$ * defines the pair-wise interaction of solvated species in solution [20]. The $\mathrm{S}_{\mathrm{V}}{ }^{*}$ values of $\mathrm{N}$-methyl glycine in aqueous paracetamol solution at different temperatures are reported in Table 4. The $\mathrm{S}_{\mathrm{V}}{ }^{*}$ value in our present study is least in $0.03 \mathrm{M} \mathrm{N}$-methyl glycine at $308 \mathrm{~K}$ and highest in $0.01 \mathrm{M} \mathrm{N}$-methyl glycine at $298.15 \mathrm{~K}$. So, $\mathrm{S}_{\mathrm{V}}{ }^{*}$ values decrease with increasing temperature and molality. This trend is exactly reverse than the $\phi v^{0}$ values explained earlier where $\phi v^{0}$ values increased 
with increasing concentrations of $\mathrm{N}$-methyl glycine and temperatures. This weakening of $\mathrm{S}_{\mathrm{V}}{ }^{*}$ values signify the presence of poor solute-solute interactions. The smaller $\mathrm{S}_{\mathrm{V}}{ }^{*}$ values than the corresponding $\phi_{\mathrm{V}}{ }^{0}$ signifies that the solute-solvent interaction is stronger than the solute-solute interaction.

Table 4 Limiting apparent molar volumes $\left(\phi_{V}\right)$, experimental slopes $\left(S_{V}^{*}\right)$, viscosity A, $B$-coefficients of aqueous $\mathrm{N}$-methyl glycine solution in paracetamol at different temperatures

\begin{tabular}{llllll}
\hline Temp. (K) & $\begin{array}{l}\phi_{V^{0} \times 10^{6}} \\
\left(\mathrm{~m}^{3} \mathrm{~mol}^{-1}\right)\end{array}$ & $\begin{array}{l}\Delta \phi_{V^{0}} \\
\left(\mathrm{~m}^{3} \mathrm{~mol}^{-1}\right)\end{array}$ & $\begin{array}{l}S_{V^{*} \times 10^{6}} \\
\left(\mathrm{~m}^{3} \mathrm{~mol}^{3 / 2} \mathrm{~kg}^{1 / 2}\right)\end{array}$ & $\begin{array}{l}B \\
\left(\mathrm{~kg}^{1 / 2} \mathrm{~mol}^{-1 / 2}\right)\end{array}$ & $\begin{array}{l}A \\
\left(\mathrm{kgmol}^{-1}\right)\end{array}$ \\
\hline $0.01 \mathrm{M} \mathrm{N}$-methyl glycine & & & & \\
$298.15 \mathrm{~K}$ & 80.114 & 1.001 & 16.544 & 0.6182 & 0.0286 \\
$303.15 \mathrm{~K}$ & 81.794 & 1.571 & 7.854 & 0.7029 & 0.0127 \\
$308.15 \mathrm{~K}$ & 82.288 & 1.253 & 6.534 & 0.8494 & 0.0086 \\
$0.02 \mathrm{M} \mathrm{N}$-methyl glycine & & & & \\
$298.15 \mathrm{~K}$ & 82.69 & 3.568 & 7.854 & 0.6572 & 0.0211 \\
$303.15 \mathrm{~K}$ & 84.471 & 4.238 & -2.39 & 0.7389 & 0.0127 \\
$308.15 \mathrm{~K}$ & 85.155 & 4.12 & -5.045 & 0.8804 & 0.0043 \\
$0.03 \mathrm{M} \mathrm{N}-\mathrm{methyl} \mathrm{glycine}$ & & & & \\
$298.15 \mathrm{~K}$ & 84.157 & 5.044 & 3.873 & 0.6856 & 0.0178 \\
$303.15 \mathrm{~K}$ & 86.381 & 6.158 & -11.03 & 0.7716 & 0.0104 \\
$308.15 \mathrm{~K}$ & 87.816 & 6.761 & -15.074 & 0.9232 & 0.0017 \\
\hline
\end{tabular}

The variation of $\phi_{V}{ }^{0}$ with temperature of $\mathrm{N}$-methyl glycine in paracetamol solution follows the polynomial [21],

$$
\phi_{V}{ }^{0}=\mathrm{a}_{0}+\mathrm{a}_{1} \mathrm{~T}+\mathrm{a}_{2} \mathrm{~T}^{2}
$$

where $\mathrm{T}$ is the temperature in $\mathrm{K}$ and $\mathrm{a}_{0}, \mathrm{a}_{1}$ and $\mathrm{a}_{2}$ are the coefficients. Values of the coefficients of the above equation for $\mathrm{N}$-methyl glycine in paracetamol solution are reported in Table 5.

The limiting apparent molar expansibilities $\left(\Phi_{E}{ }^{0}\right)$ can be determined by the following equation [22],

$$
\Phi_{E^{0}}=\left(\delta \phi_{V}{ }^{0} / \delta T\right)_{P}=\mathrm{a}_{1}+2 \mathrm{a}_{2} \mathrm{~T}
$$

The values of $\Phi_{E}{ }^{0}$ of $\mathrm{N}$-methyl glycine in paracetamol solution at 298.15 $\mathrm{K}, 303.15 \mathrm{~K}$ and $308.15 \mathrm{~K}$ are evaluated and reported in Table 5 .

The $S_{V}^{*}$ is not the only parameter for estimating the structure-making or breaking nature of any solute [30]. Hepler proposed a different technique to inspect the structure-making and breaking ability of the solute in aqueous solution from the following thermodynamic expression [23],

$$
\left(\delta \Phi_{E}{ }^{0} / \delta T\right)_{P}=\left(\delta^{2} \phi_{V}{ }^{0} / \delta T^{2}\right)_{P}=2 \mathrm{a}_{2}
$$

According to Hepler the structure making solutes should have positive $\left(\delta \Phi_{E}{ }^{0} / \delta T\right)_{P}$ values, whereas structure-breaking solutes should have negative values[24, 25]. The $\left(\delta \Phi_{E}{ }^{0} / \delta T\right)_{P}$ values of $\mathrm{N}$-methyl glycine in paracetamol solution have been provided in Table 5 . It is apparent that $\left(\delta^{2} \phi_{V}{ }^{0} / \delta T^{2}\right)_{P}$ values are negative for $\mathrm{N}$-methyl glycine in paracetamol solution which signifies that paracetamol perform as structure breaker in aq. nicotinic acid solution.

Table 5 Values of empirical coefficients ( $a_{0}, a_{1}$, and $a_{2}$ ) of $0.01 \mathrm{M}, 0.02 \mathrm{M}$ and $0.03 \mathrm{M}$ $\mathrm{N}$-methyl glycine in paracetamol solution at $298.15 \mathrm{~K}, 303.15 \mathrm{~K}$ and $308.15 \mathrm{~K}$

\begin{tabular}{lllll}
\hline $\begin{array}{l}\text { Molality of } \\
\text { N-methyl glycine }\end{array}$ & $\begin{array}{l}a_{0} \times 10^{6} \\
\left(\mathrm{~m}^{3} \mathrm{~mol}^{-1}\right)\end{array}$ & $\begin{array}{l}a_{1} \times 10^{6} \\
\left(\mathrm{~m}^{3} \mathrm{~mol}^{-1} \mathrm{~K}^{-1}\right)\end{array}$ & $\begin{array}{l}a_{2} \times 10^{6} \\
\left(\mathrm{~m}^{3} \mathrm{~mol}^{-1} \mathrm{~K}^{-2}\right)\end{array}$ & $\left(\delta \Phi_{E}{ }^{0} / \delta T\right)_{P}$ \\
\hline $0.01 \mathrm{M}$ & -2161.8 & 14.59 & -0.0237 & -0.0474 \\
$0.02 \mathrm{M}$ & -1951 & 13.19 & -0.0214 & -0.0428 \\
$0.03 \mathrm{M}$ & -1473.2 & 9.926 & -0.0158 & -0.0316 \\
\hline
\end{tabular}

The limiting apparent molar volume of transfer, $\Delta \phi v^{0}$ for N-methyl glycine in paracetamol solution may be expressed as follows:

$\Delta \phi_{\mathrm{v}^{0}}(\mathrm{~N}$-methyl glycine $)=\phi_{\mathrm{v}^{0}}(\mathrm{~N}-$-methyl glycine in paracetamol $)-\phi_{\mathrm{v}^{0}}($ in water)

The $\Delta \phi_{\mathrm{v}}{ }^{0}$ value provide the idea about the nature solute-solvent interactions. The limiting apparent molar volume of transfer may be analyzed in the light of co-sphere overlap model given by Friedman and Krishnan [26]. According to the model positive $\Delta \phi v^{0}$ value specifies the existence of hydrophilic-hydrophilic, ion-hydrophilic and ion-ion interactions, whereas the negative $\Delta \phi v^{0}$ value specifies the hydrophobichydrophobic interactions [27, 28]. The interactions between N-methyl glycine and paracetamol in aqueous medium may be of following categories.

https://doi.org/10.30799/jacs.199.18040403 i. Ionic-ionic interaction of the $\mathrm{H}^{+}$ion of water and $\mathrm{N}$-methyl glycine with the -COO- ion of $\mathrm{N}$-methyl glycine

ii. H-bond between - $\mathrm{COOH}$ (N-methyl glycine) and -OH (paracetamol) and also with water.

iii. Ionic-hydrophilic interaction of polar end of water with - $\mathrm{COO}^{-}$ion of $\mathrm{N}$-methyl glycine and -OH group of paracetamol.

iv. Ionic- hydrophilic interactions of - $\mathrm{COOH}$ ( $\mathrm{N}$-methyl glycine) and $-\mathrm{OH}$ (paracetamol) with the $\mathrm{H}^{+}$and $\mathrm{OH}^{-}$ion of water.

v. Hydrophobic-hydrophobic interaction of non-polar part of N-methyl glycine and paracetamol.

The interactions of categories (i), (ii), (iii) and (iv) have positive contributions to $\phi \mathrm{v}^{0}$ values while interaction of types $(\mathrm{v})$ has negative contribution to $\phi_{\mathrm{V}^{0}}$ values [29-31]. The positive $\Delta \phi_{\mathrm{V}}{ }^{0}$ value indicates that the hydrophilic-hydrophilic and ion-ion interactions are in domination over hydrophobic-hydrophobic and ionic-hydrophobic interactions. It is also seen that $\Delta \phi_{\mathrm{v}}{ }^{0}$ values are increasing with increase in molality of $\mathrm{N}$ methyl glycine. The intermolecular distance between $\mathrm{N}$-methyl glycine and paracetamol decreases with increasing concentration of $\mathrm{N}$-methyl glycine as a result the hydrophobic-hydrophobic and ionic-hydrophobic interactions increase with molality. Similar result can also be obtained from the following expression given by Franks et al [32],

$$
\phi \mathrm{v}^{0}=\phi \mathrm{W}+\phi \mathrm{V}-\phi \mathrm{S}
$$

where $\phi \mathrm{W}$ is correlated with Van Der Waals volume, $\phi \mathrm{V}$ is the volume correlated with voids or empty space and $\phi S$ is correlated with shrinkage volume due to electrostriction. The value $\phi \mathrm{W}$ and $\phi \mathrm{V}$ will remain same for the same class of solutes in aqueous solutions and only the volume due to electrostriction will vary. The hydrophilic-hydrophilic, ion-ion and ionhydrophilic interactions will increase with increasing molality of $\mathrm{N}$-methyl glycine and as a result $\phi S$ value will decrease [33]. For this reason, $\phi v^{0}$ values increase with increasing molality of N-methyl glycine.

The volumetric pair wise and triple ion interactions may be estimated from the following equation given by McMillan-Mayer [34],

$$
\Delta \phi v^{0}=2 Y_{X Y M}+3 Y_{X Y Y m}{ }^{2}
$$

where $\mathrm{Y}_{\mathrm{AB}}, \mathrm{Y}_{\mathrm{ABB}}$ and $\Delta \phi_{\mathrm{V}}{ }^{0}$ are pair and triple ion interaction coefficients, limiting apparent molar volume of transfer respectively and $\mathrm{X}$ and $\mathrm{Y}$ represent $\mathrm{N}$-methyl glycine and paracetamol respectively. The coefficients $\mathrm{Y}_{\mathrm{AB}}$ and $\mathrm{Y}_{\mathrm{ABB}}$ are estimated by putting the $\Delta \phi \mathrm{v}^{0}$ values at diverse molarities of $\mathrm{N}$-methyl glycine in presence of paracetamol in the above expression and mentioned in Table 6 . It is observed that $Y_{X Y}$ values are positive whereas $\mathrm{Y}_{\mathrm{XYY}}$ values are negative for $\mathrm{N}$-methyl glycine in presence of paracetamol in aqueous medium at different temperatures. The positive values of $Y_{X Y}$ suggest that existing interactions in our studied solutions are mostly pair wise which arises from hydrophilic-hydrophilic and ion-ion interactions between solute and co-solute in aqueous medium [35].

Table 6 Pair, $V_{\mathrm{AB}}$, and Triple, $V_{\mathrm{ABB}}$, interaction coefficients of $\mathrm{N}$-methyl glycine in aqueous solution of paracetamol at $298.15 \mathrm{~K}, 303.15 \mathrm{~K}$ and $308.15 \mathrm{~K}$ temperatures

\begin{tabular}{llllll}
\hline $\mathrm{V}_{\mathrm{AB}}$ & $\mathrm{V}_{\mathrm{ABB}}$ & $\mathrm{V}_{\mathrm{AB}}$ & $\mathrm{V}_{\mathrm{ABB}}$ & $\mathrm{V}_{\mathrm{AB}}$ & $\mathrm{V}_{\mathrm{ABB}}$ \\
$\mathrm{m}^{3} \mathrm{~mol}^{-2} \mathrm{~kg}$ & $\mathrm{~m}^{3} \mathrm{~mol}^{-2} \mathrm{~kg}^{2}$ & $\mathrm{~m}^{3} \mathrm{~mol}^{-2} \mathrm{~kg}$ & $\mathrm{~m}^{3} \mathrm{~mol}^{-2} \mathrm{~kg}^{2}$ & $\mathrm{~m}^{3} \mathrm{~mol}^{-2} \mathrm{~kg}$ & $\mathrm{~m}^{3} \mathrm{~mol}^{-2} \mathrm{~kg}^{2}$ \\
\hline $298.15 \mathrm{~K}$ & & $303.15 \mathrm{~K}$ & & $308.15 \mathrm{~K}$ & \\
78.0000 & -372.23 & 99.3100 & 221.1200 & 102.3700 & -187.77 \\
\hline
\end{tabular}

\subsection{Viscosity Calculation}

The viscosity data were fit into Jones-Dole equation [36],

$$
\left(\eta / \eta_{0}-1\right) / \sqrt{m}=A+B \sqrt{m}
$$

where, $\eta_{0}$ and $\eta$ are the viscosities of the solvent and solution respectively. A plot of $\left(\eta / \eta_{0}-1\right) / \sqrt{m}$ against $\sqrt{\mathrm{m}}$ gives a straight line with an intercept "A" and a slope of "B". The $\left(\eta / \eta_{0}-1\right) / \sqrt{m}$ values of $N$-methyl glycine of different molarities in aqueous paracetamol solution are reported in Table 3. The viscosity coefficients $A$ and $B$ values are reported in Table 4 and the variation of $\mathrm{B}$ with temperature of $\mathrm{N}$-methyl glycine is shown in Fig. 4. The viscosity $B$-coefficient signifies solute-solvent interaction and provides valuable information concerning the solvation of the solute in solution [37, 38]. A close inspection reveals that B-value is higher for $0.03 \mathrm{M} \mathrm{N}$-methyl glycine solution at $308.15 \mathrm{~K}$ and lowest at $0.01 \mathrm{M}$ solution at $298.15 \mathrm{~K}$. So, solute-solvent interactions increase with increasing molarity and temperature. Viscosity A coefficient denotes solute-solute interaction. It is reflected from the Table 4 that the values of $A$ coefficient decrease with the increase in molarity and temperature of $\mathrm{N}$-methyl glycine in aqueous solution of paracetamol. Hence solute-solute interaction diminishes with molarity of $\mathrm{N}$-methyl glycine and also with temperature in $\mathrm{K}$. 


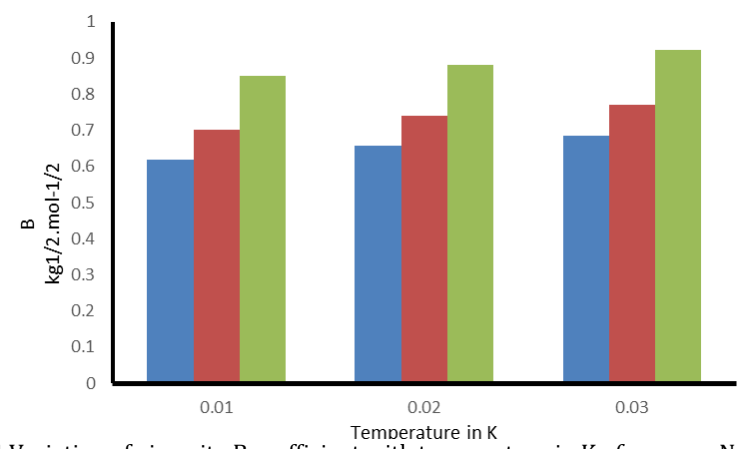

Fig. 4 Variation of viscosity B coefficient with temperature in $\mathrm{K}$ of aqueous $\mathrm{N}$-methyl glycine in paracetamol solution

\subsection{Refractive Index Calculation}

The molar refraction, $R_{M}$ for any compound in its aqueous solution may be determined from the Lorentz-Lorenz relation [39]:

$$
\mathrm{RM}=\{(\mathrm{nD} 2-1) /(\mathrm{nD} 2+2)\}(\mathrm{M} / \rho)
$$

where, $R_{M}, \rho, M$ and $n_{D}$ are the molar refraction, density of solution, molar mass and refractive index, respectively. The refractive index of a material is defined as $c_{0} / c$, where $c$ is the speed of light in any medium and $c_{0}$ the speed of light in vacuum. The light is refracted more for the substance of higher refractive index [40]. According to Deetlefs et al. [41] the molar refraction of a substance will be higher when the molecules in any solution are more tightly packed. The values of RM are shown in Table 3. The increase in molar refraction values with increase in molarity of $\mathrm{N}$-methyl glycine in aqueous paracetamol solution indicates close packing of molecules in the mixture resulting in maximum solute-solvent interactions.

\section{$3.4{ }^{1}$ H NMR Spectroscopy}

Various spectroscopy may be employed to examine the diverse interaction playing in solution of any compound [42-46]. ${ }^{1} \mathrm{H}$ NMR Spectroscopy of pure N-methyl glycine, paracetamol and their solution are recorded in $\mathrm{D}_{2} \mathrm{O}$ at $298.15 \mathrm{~K}$ and shown in Fig. 5.

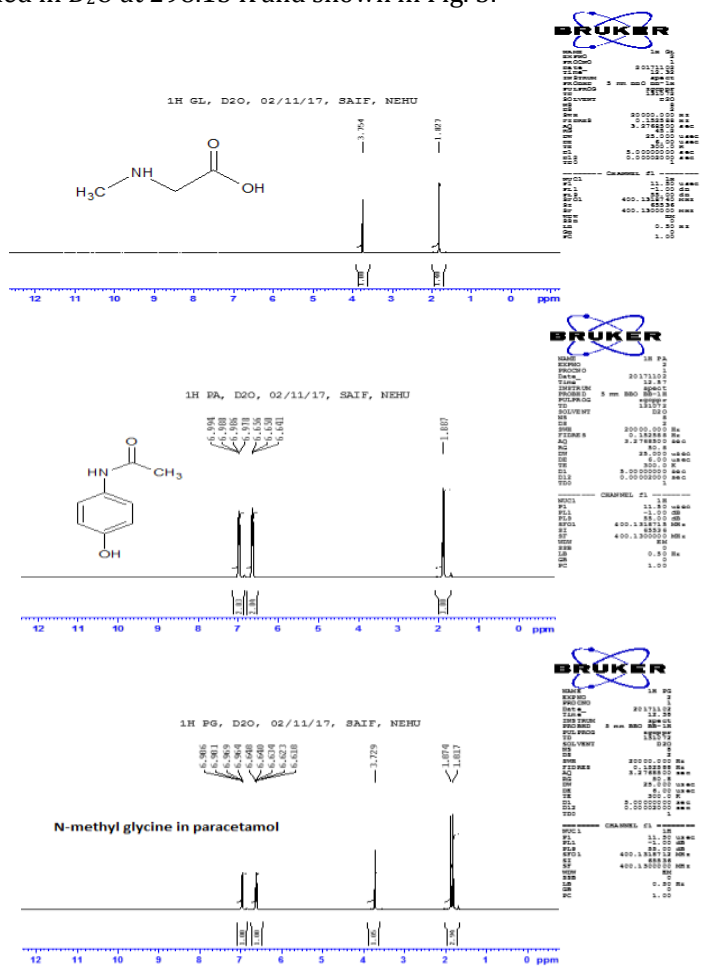

Fig. $5^{1} \mathrm{H}$ NMR spectra of $\mathrm{N}$-methyl glycine, paracetamol and their solution in D2O

Up field chemical shift of protons of methyl group and methylene group of glycine in aqueous solution of paracetamol from its pure form may be regarded due to the involvement of adjacent - $\mathrm{NH}$ - and - $\mathrm{COOH}$ groups in $\mathrm{H}$ bonding with the $-\mathrm{OH}$ group of paracetamol. However higher $\Delta \delta$ for methylene group than the methyl group indicates that $-\mathrm{COOH}$ form stronger H-bond with - $\mathrm{OH}$ group of paracetamol than the $-\mathrm{NH}$ - group. Similar up field chemical shift of protons adjacent to - $\mathrm{OH}$ group of paracetamol takes place which may also be considered due to its involvement in $\mathrm{H}$-bonding with favorable groups of $\mathrm{N}$-methyl glycine. The https://doi.org/10.30799/jacs.199.18040403 extend of $\Delta \delta$ for protons at o-position of -OH group is larger than the protons at p-position which indicates that $-\mathrm{OH}$ is more favorable in forming $\mathrm{H}$-bond than the - $\mathrm{NH}$ - group of paracetamol.

${ }^{1} \mathrm{H}$ NMR data: N-methyl glycine: $\left[{ }^{1} \mathrm{H}\right.$ NMR $\left.\left(300 \mathrm{MHz}, \mathrm{D}_{2} \mathrm{O}\right)\right]: \delta 1.827(3 \mathrm{H}$ s), 3.754(2H, s) paracetamol: [ ${ }^{1} \mathrm{H}$ NMR $\left.\left(300 \mathrm{MHz}, \mathrm{D}_{2} \mathrm{O}\right)\right]$ : $\delta 1.887(3 \mathrm{H}, \mathrm{s})$, $6.656(2 \mathrm{H}, \mathrm{d}), 6.988(2 \mathrm{H}, \mathrm{d})$ solution of $\mathrm{N}$-methyl glycine and paracetamol $\left[{ }^{1} \mathrm{H}\right.$ NMR $\left.\left(300 \mathrm{MHz}, \mathrm{D}_{2} \mathrm{O}\right)\right]: \delta 1.817(3 \mathrm{H}, \mathrm{s}), 1.874(3 \mathrm{H}, \mathrm{s}), 3.729(2 \mathrm{H}, \mathrm{s}) 6.634$ $(2 \mathrm{H}, \mathrm{d}), 6.981(2 \mathrm{H}, \mathrm{d})$

\section{Conclusion}

The limiting apparent molar volume $\left(\phi_{v^{0}}\right)$ and viscosity $B$-coefficient and molar refraction $\left(\mathrm{R}_{\mathrm{M}}\right)$ values indicate the existence of strong solutesolvent interactions between $\mathrm{N}$-methyl glycine and paracetamol in aqueous medium. The solute-solvent interactions enhances with increasing molality of N-methyl glycine and temperature. On the other hand, the solute-solute interactions diminish with increasing molality of $\mathrm{N}$-methyl glycine and temperature. The nature of solute-solvent interactions was evaluated from the limiting apparent molar volume of transfer $\left(\phi_{V}{ }^{0}\right)$ values. It was also observed that the interaction between our studied solute and co-solute in aqueous medium was mostly pair wise. ${ }^{1} \mathrm{H}$ NMR Spectroscopy concretely support our findings obtained from volumetric, viscometric and refractive index study.

\section{Acknowledgement}

The authors are grateful to the UGC supported Major research project, SAP, DRS-III for financial support in order to continue this research work One of the authors, Prof. M.N. Roy is thankful to University Grant Commission, New Delhi, Government of India for being awarded one-time grant under Basic Scientific Research via the grant-in-Aid No. F.4-10/2010 (BSR) regarding his active service for augmenting of research facilities to facilitate further research work.

\section{References}

[1] P.H. Von Hippel, T. Schleich, Ion effects on the solution structure of biological macromolecules, Acc. Chem. Res. 2 (1969) 257-265.

[2] F. Franks, Protein stability: the value of old literature, Biophys. Chem. 96 (2002) 117-127.

[3] Taravati, M. Shokrzadeh, A.G. Ebadi, P. Valipour, A.T.M. Hassan, F. Farrokhi, Various effects of sugar and polyols on the protein structureband function: role as osmolyte on protein stability, World Appl. Sci. J. 2 (2007) 353-362.

[4] K. Gekko, Mechanism of polyol-induced protein stabilization: solubility of amino acids and diglycine in aqueous polyol solutions, J. Biochem. 90 (1981) 1633-1641.

[5] F.J. Millero, A. Lo Surdo, C. Shin, The apparent molal volumes and adiabatic compressibilities of aqueous amino acids at $25^{\circ} \mathrm{C}$, J. Phys. Chem. 82 (1978) 784-792.

[6] E.D. Belay, J.S. Bresse, R.C. Holman, A.S. Khan, A. Shahriari, L.B. Schonberger, Reye's syndrome in the United States from1981 through 1997, N. Engl. J. Med. 340 (1999) 1377-1382.

[7] J.R. Vane, Inhibition of prostaglandin synthesis as a mechanism of action for aspirin-like drugs, Nat. New Bio. 231 (1971) 232-235.

[8] L.F. Prescott, G.C. Speirs, J.A. Critchley, R.M. Temple, R.J. Winny, Paracetamo disposition and metabolite kinetics in patients with chronic renal failure, Eur. J. Clin. Pharmacol. 36 (1989) 291-297.

[9] L.A. Pini, G. Vitale, A. Ottani, M. Sandrini, Naloxone-reversible antinociception by paracetamol in the rat, J. Pharmacol. Exp. Ther. 280 (1997) 934-940.

[10] B.H. Rumack, Aspirin versus acetaminophen: a comparative view, Pediatrics 62(5 Pt 2 Suppl) (1978) 943-946.

[11] M.J. Earle, K.R. Seddon, Green solvents for the future, Pure Appl. Chem. 72 (2000) 1391-1398.

[12] F.A. Robinson, The Vitamin B-complexes, Chapman \& Hall Publication, London, 1951.

[13] C.A. Elvehjem, L. Teply, The structure and estimation of natural products functionally related to nicotinic acid, J. Chem. Rev. 33(3) (1943) 185-208.

[14] A.N. Nesmeyanov, Fundamentals of organic chemistry, Mir Publication, Moscow, 1981.

[15] A.S. Fauci, E. Braunwald, K.J. Isselbacher, J.D. Wilson, J.B. Martin, et al., Harrison's principles of internal medicine, McGraw-Hill, New York, 1998.

[16] J. Block, Kirk-Othmer encyclopedia of chemical technology, Wiley, NJ, 1996.

[17] L.A. Carlson, Nicotinic acid: The broad-spectrum lipid drug. A 50th Anniversary review, Jour. Int. Medi. 258(2) (2005) 94-114.

[18] D. Ekka, M.N. Roy, Quantitative and qualitative analysis of ionic solvation of individual ions of imidazolium based ionic liquids in significant solution system by conductance and FT-IR spectroscopy, RSC Adv. 4(38) (2014) 19831-19845.

[19] T. Welton, Room temperature ionic liquids, Solvents for synthesis and catalysis, Chem. Rev. 99(8) (1999) 2071-2084.

[20] M.J. Earcle, K.R. Seddon, Green solvents for the future, Pure Appl. Chem. 72 (2000) 1391-1398.

[21] J. Dupont, R.F. Desouza, P.A. Suarez, Ionic liquid (molten salt) phase organometallic catalysis, Chem. Rev. 102(10) (2002) 3667-3692. 
[22] N.V. Plechkova, K.R. Seddon, Applications of ionic liquids in the chemical industry, Chem. Soc. Rev. 37 (2008) 123-150.

[23] F. Endres, S.Z. El Abedin, Air and water stable ionic liquids in physical chemistry, Phys. Chem. Chem. Phys. 8(1) (2006) 2101-2116.

[24] P. Wang, S.M. Zakeeruddin, J.E. Moser, M. Gratzel, A new ionic liquid electrolyte enhances the conversion efficiency of dye-sensitized solar cells, J. Phys. Chem. B 107(48) (2003) 13280-13285.

[25] J.M. McDowall, C.A. Vincent, Viscosity behaviour of some simple electrolytes in for mamide solution, Jour. Chem. Soc. Farad. Trans. 1 (1974) 1862-1868.

[26] M.R. Deck, K.J. Bird, Solvation of ions, Partial molal volumes of single ions in protic and dipolar aprotic solvents, Aust. Jour. Chem. 28(5) (1975) 955-963.

[27] M.N. Roy, B. Sinha, R. Dey, A. Sinha, Solute-solvent and solute-solute interactions of resorcinol in mixed 1, 4-dioxane-water systems at different temperatures, Int. J. Thermophy. 26(5) (2005) 1549-1563.

[28] M.N. Roy, R. Dewan, P.K. Roy, D. Biswas, Apparent molar volumes and viscosity B-coefficients of carbohydrates in aqueous cetrimonium bromide solutions at (298.15, 308.15, and 318.15) K, Jour. Chem. Eng. Data 55(9) (2010) 3617-3624.

[29] A. Bhattacharjee, M.N. Roy, Ion association and solvation behavior of tetraalkylammonium iodides in binary mixtures of dichloromethane $+\mathrm{N}, \mathrm{N}$ dimethylformamide probed by a conductometric study, Phys. Chem. Chem. Phys. 12(43) (2010) 14534-14542.

[30] D. Ekka, M.N. Roy, Conductance, a contrivance to explore ion association and solvation behavior of an ionic liquid (tetrabutylphosphonium tetrafluoroborate) in acetonitrile, tetrahydrofuran, 1, 3-Dioxolane and their binaries, Jour. Phys. Chem. B 116(38) (2012) 11687-11694.

[31] D. Ekka, M.N. Roy, Molecular interactions of $\alpha$-amino acids insight into aqueous $\beta$-cyclodextrin systems, Amino Acids 45(4) (2013) 755-777.

[32] M.N. Roy, D. Ekka, S. Saha, M.C. Roy, Host-guest inclusion complexes of $\alpha$ and $\beta$ cylodextrins with $\alpha$-amino acids, RSC Adv. 4(80) (2014) 42383-42390.

[33] M.N. Roy, T. Ray, M.C. Roy, B. Datta, Study of ion-pair and triple-ion origination of an ionic liquid ([bmmim] [BF4]) predominant in solvent systems, RSC Adv. $4(107)$ (2014) 62244-62254.

[34] R. Gopal, M.A. Siddique, A study of ion-solvent interactions of some tetraalkylammonium and common ions in N-methyl acetamide from apparent molar volume data, Jour. Phys. Chem. 72 (1969) 1814-1817.
[35] M.N. Roy, A. Jha, A. Choudhury, Densities, viscosities and adiabatic compressibilities of some mineral salts in water at different temperatures, Jour. Chem. Eng. Data 4 (2004) 291-296.

[36] E. Ayranci, Apparent molar volume and viscosity of compounds with asymmetric carbon atoms, J. Chem. Eng. Data 42(5) (1997) 934-937.

[37] F.J. Millero, J.H. Knox, Apparent molal volumes of aqueous sodium fluoride, sodium sulfate, potassium chloride, potassium sulfate, magnesium chloride and magnesium sulfate solutions at 0 deg. and $50 \mathrm{deg}$, Jour. Chem. Eng. Data 18 (1973) 407-411.

[38] M.N. Roy, D. Ekka, R. Dewan, Physico-chemical studies of some bio-active solutes in pure methanoic acid, Acta Chim. Slov. 58(4) (2011) 792-796.

[39] D. Denby, Chemistry Review, University of New York, New York, 1996

[40] M.N. Roy, I. Banik, Study of solute-solvent interaction of some bio-active solutes prevailing in aqueous ascorbic acid solution, Jour. Mol. Liq. 169 (2012) 8-14.

[41] G. Jones, M. Dole, The viscosity of aqueous solutions of strong electrolytes with special reference to barium chloride, Jour. Am. Chem. Soc. 51 (1929) 29502964.

[42] K. Das, M.C. Roy, M.N. Roy, Conjoint beneficial impacts of lithium-ion along with aqueous vitamin in driven rechargeable batteries and also in neurotransmitter drugs, J. Adv. Chem. Sci. 3(1) (2017) 428-433.

[43] T. Ray, M.N. Roy, Study to explore assorted interfaces of an ionic liquid prevailing in solvent systems by physicochemical approach, RSC Adv. 5 (2015) 89431-89440.

[44] J. Poznanski, A. Ejchart, K.L. Wierzchowski, M. Ciurak, ${ }^{1} \mathrm{H}-$ and ${ }^{13} \mathrm{C}-\mathrm{NMR}$ investigations on cis-trans isomerization of proline peptide bonds and conformation of aromatic side chains in H-Trp-(Pro)n-Tyr-OH peptides, Biopolym. 33(5) (1993) 781-795.

[45] K. Das, M. Chandra Roy, B. Rajbanshi, M.N. Roy, Assorted interactions of amino acids prevailing in aqueous vitamin $\mathrm{C}$ solutions probed by physicochemical and ab-initio contrivances, Chem. Phys. Lett. 687 (2017) 209-221.

[46] R.F. Chen, Fluorescence quantum yields of tryptophan and tyrosine, Anal. Lett. 1 (1967) 35-42. 